\title{
Does Retrograde Diastolic Flow in the Descending Aorta Signify Impaired Systemic Perfusion in Preterm Infants?
}

\author{
ALAN M. GROVES, CARL A. KUSCHEL, DAVID B. KNIGHT, AND JON R. SKINNER \\ Neonatal Unit [A.M.G.], Queen Charlotte's and Chelsea Hospital, London, W12 OHS, United Kingdom; Newborn Services [C.A.K., \\ D.B.K.], Auckland City Hospital, Auckland, 1023, New Zealand; Paediatric and Congenital Cardiac Services [J.R.S.], Starship Children's \\ Hospital, Auckland, 1023, New Zealand
}

\begin{abstract}
High-volume systemic-to-pulmonary ductal shunting occurs frequently in preterm infants and is indicated by diastolic flow reversal in the descending aorta (DAo). We studied the relationship between ductal diameter, diastolic DAo reversal, and left ventricular output (LVO); and superior vena caval (SVC) flow (upper body perfusion) and DAo flow (lower body perfusion) in preterm $(<31$ wk) infants. Echocardiographic assessments were performed at 5, 12, 24 , and $48 \mathrm{~h}$ postnatal age (80 infants, median gestation $28 \mathrm{wk}$, $1060 \mathrm{~g}$ ). Incidence of ductal patency fell from $100 \%$ at $5 \mathrm{~h}$ to $72 \%$ at $48 \mathrm{~h}$; incidence of pure systemic-to-pulmonary shunting increased from $66 \%$ to $95 \%$ of infants with patent ducts. In infants with duct diameter greater than the median, 35-48\% of infants had DAo flow reversal. In infants with duct diameter greater than median, DAo reversal was associated with $23-29 \%$ increases in LVO at 5-48 h, and $35 \%$ decreases in DAo flow volume at $24-48 \mathrm{~h}$, but no differences in SVC flow. In conclusion, a large duct with left-to-right shunting is common in preterm infants. Retrograde DAo flow is a marker of high-volume shunt, evidenced by increased LVO. Preterm infants with high-volume ductal shunt may have preserved upper body perfusion but reduced lower body perfusion. (Pediatr Res 63: 89-94, 2008)
\end{abstract}

$\mathrm{T}$ he clinical significance of shunting through the patent ductus arteriosus in the premature newborn infant remains uncertain (1-4). It is clear that prolonged patency of the ductus arteriosus is seen in preterm infants with respiratory distress (5), and can be associated with significant volume of systemic-to-pulmonary shunting (6). In addition, prolonged ductal patency is associated with a variety of adverse outcomes in preterm infants (7). However, a causative association between ductal shunting and adverse outcome has not been established $(8,9)$, and clinical trials of therapeutic intervention have not demonstrated reductions in morbidity (1). There is increasing awareness that ductal patency may not be a primary pathologic entity but rather an epiphenomenon of prematurity itself (10).

Circulatory impact of ductal shunt depends on the volume of shunt and the ability of the myocardium to produce a compensatory increase in left ventricular output (LVO). It has previously been suggested that in the first postnatal days shunt volume through the ductus would be low due to the relatively

Received April 19, 2007; accepted August 22, 2007.

Correspondence: Alan Groves, M.D., Neonatal Unit, Queen Charlotte's and Chelsea Hospital, Du Cane Road, London, W12 0HS, UK; e-mail: alan.groves@imperial.ac.uk AMG was supported by a grant from The Southern Trust. balanced pulmonary and systemic arterial pressures at this time (11). However, there is now substantial evidence that pulmonary pressure in surfactant treated infants falls rapidly after birth (12,13). High-volume ductal shunt, as evidenced by reversal of blood flow during diastole in the descending aorta (DAo), has been seen as early as $7 \mathrm{~h}$ after birth (8), and may occur days before clinical signs appear (5).

LVO has been shown to increase with increased ductal shunting in many preterm infants (14). However, it is possible that the immature myocardium has a limited ability to increase output in the first postnatal day (15). The combination of high-volume ductal shunt without an increase in cardiac output could lead to systemic hypoperfusion. Volume of blood flow in the superior vena cava (SVC) is a marker of upper body, including cerebral, perfusion (16), and low SVC flow is associated with intraventricular hemorrhage (17), decreased electroencephalogram (EEG) activity (18), and impaired neurodevelopmental outcome (19). Volume of blood flow in the descending aorta is not well studied in neonates but is considered a marker of lower body perfusion (20-22).

Simply examining associations between ductal size and systemic perfusion may produce erroneous conclusions. If ductal patency is predominantly a marker of immaturity rather than a primary pathologic phenomenon $(7,10)$, increased ductal size may be associated with, but not causative of, impaired systemic perfusion. The impaired systemic perfusion may be predominantly due to myocardial immaturity and severity of respiratory distress, which are themselves related to prolonged ductal patency.

The aims of this study were 1) to investigate patterns of ductal shunting in the first $48 \mathrm{~h}$ of postnatal life in preterm infants undergoing current patterns of neonatal care, and 2) to examine circulatory impact of high-volume ductal shunt as evidenced by DAo flow reversal, as opposed to simply ductal diameter.

\section{METHODS}

Subjects. Infants $<31$ wk completed gestation were recruited to the study at National Women's Hospital, Auckland, between December 1, 2002, and May 1, 2004. The study was approved by the local ethics committee and informed written parental consent was obtained in each case.

Abbreviations: DAo, descending aorta; LVO, left ventricular output; RVO, right ventricular output; SVC, superior vena cava 
Table 1. Duct diameter and direction of shunt in 80 preterm infants at 5, 12, 24, and 48 h postnatal age

\begin{tabular}{|c|c|c|c|c|}
\hline & $5 \mathrm{~h}$ & $12 \mathrm{~h}$ & $24 \mathrm{~h}$ & $48 \mathrm{~h}$ \\
\hline Median duct diameter (Range) & $1.9 \mathrm{~mm}(1.1-3.9)$ & $1.5 \mathrm{~mm}(0-3.3)$ & $1.7 \mathrm{~mm}(0-3.4)$ & $1.4 \mathrm{~mm}(0-3.1)$ \\
\hline Left to right & $53(66 \%)$ & $63(79 \%)$ & $55(69 \%)$ & $54(68 \%)$ \\
\hline Bidirectional & $24(30 \%)$ & $11(14 \%)$ & $7(9 \%)$ & $3(4 \%)$ \\
\hline Right to left & $3(4 \%)$ & $0(0 \%)$ & $0(0 \%)$ & $0(\%)$ \\
\hline Duct closed & $0(0 \%)$ & $6(7 \%)$ & $18(22 \%)$ & $23(28 \%)$ \\
\hline
\end{tabular}

Measurements. Echocardiography was performed as close as possible to 5 , 12,24 , and $48 \mathrm{~h}$ postnatal age by one of two investigators (AMG and CAK). All scans were performed with an ATL 3000 ultrasound scanner (Advanced Technological Laboratories, Bothell, WA) using a 7-MHz phased-array probe. Images were recorded onto videotape and measurements undertaken away from the cotside by one investigator (AMG). Investigators were not masked as to the postnatal age or clinical status of the infants.

Assessments of SVC (16) and DAo blood flows (22), LVO (14), and right ventricular output (RVO) (23) were performed as previously described. Reversal of DAo flow was assessed from both the subcostal and suprasternal views (22). Ductal diameter was assessed at the point of maximal constriction by color Doppler from the high left parasternal "ductal" view, with care taken to minimize color gain such that no interference was seen outside the vessel walls (24).

Data analysis. At each time point, the relationships between ductal diameter and measurements of perfusion were assessed using linear regression. Adjustment for clinically relevant confounding variables was carried out using multiple linear regressions. Initial variables included were birth weight, intrauterine growth restriction [birth weight SD (z-) score], and antenatal steroid use. Adjustment for severity of respiratory disease was carried out using mean airway pressure (MAP), fraction of inspired oxygen $\left(\mathrm{FiO}_{2}\right)$ and $\mathrm{PCO}_{2}$ (if measured within $2 \mathrm{~h}$ of the echocardiogram). The level of ventilatory support received was determined by the attending clinicians, who were unaware of the results of the echocardiograms.

SVC flow, DAo flow, LVO, and RVO at each scan were compared between infants with duct diameter above and below the median using a Mann-Whitney test. To delineate the influence of ductal shunt volume rather than simply ductal size, flow volumes were compared between infants with and without diastolic DAo reversal within the group of infants with duct diameter above the median. The ratio of lower body to upper body perfusion was estimated as DAo flow/SVC flow. In all cases, statistical significance was taken where $p<0.05$.

\section{RESULTS}

Eighty infants with median (range) gestation 28 (24-30) wk and birth weight $1060(510-1900) \mathrm{g}$ were studied. Forty $(50 \%)$ infants were male and $76(95 \%)$ had been exposed to antenatal steroids. On admission, 43 (54\%) infants required mechanical ventilation, $34(42 \%)$ received continuous positive airway pressure. Thirteen (16\%) infants subsequently developed periventricular hemorrhage and $6(8 \%)$ died before hospital discharge. No infant received treatment targeted at promoting ductal closure before the echocardiogram at $24 \mathrm{~h}$. One infant who suffered significant pulmonary hemorrhage received indomethacin just before their 48-h echocardiogram.

The median ductal diameter and direction of ductal shunting at each scan are shown in Table 1.

Impact of duct at $5 \boldsymbol{h}$. At $5 \mathrm{~h}$ postnatal age, ductal diameter was not associated with SVC flow, DAo flow, LVO, or RVO on univariate analysis. There were no differences in measurements of perfusion between infants with duct diameter greater than and less than the median (Table 2).

Of the 40 infants with duct diameter greater than the median of $1.9 \mathrm{~mm}, 19(48 \%)$ had reversal of diastolic DAo flow. These 19 infants had an increased LVO $(p=0.05)$ when compared with infants with large ducts but without reversal of diastolic DAo flow. However, there were no differences in SVC flow $(p=0.28)$, DAo flow $(p=0.15)$, or RVO $(p=$ 0.80 ) between the groups.

Impact of duct at $12 \mathrm{~h}$. At $12 \mathrm{~h}$ postnatal age, ductal diameter was inversely related to SVC flow volume on univariate analysis $\left(\mathrm{R}^{2}=0.095, p=0.006\right)$, but was not associated with volume of DAo flow, LVO, or RVO. The inverse association between ductal diameter and SVC flow remained significant ( $p=0.001$ ) when correcting for birth weight, birth weight $\mathrm{z}$-score, and antenatal steroids with multivariate analysis. When correcting for respiratory status (MAP, $\mathrm{FiO}_{2}$ and $\mathrm{P}_{2}$ ), the association between ductal diameter and $\mathrm{SVC}$ flow was no longer significant $(p=0.24)$. However, only 44 infants had $\mathrm{PCO}_{2}$ levels measured at the time of the echocardiogram.

Infants with ductal diameter greater than the median had lower SVC flow than infants with smaller ducts $(p=0.02)$, but there were no differences in DAo flow, LVO, or RVO between the groups (Table 2).

Of the 44 infants with ductal diameter greater than the median at $12 \mathrm{~h}, 15$ (34\%) had reversal of diastolic DAo flow. These 15 infants had increased LVO $(p=0.0007)$, and showed a trend toward decreased DAo flow volume $(p=$ 0.06) when compared with infants with large ducts but no reversal of diastolic DAo flow. However, there were no differences in SVC flow $(p=0.76)$ or RVO $(p=0.94)$ between the groups. Ratio of lower body to upper body perfusion showed a trend to be lower in infants with DAo flow reversal (1.36 versus $1.52, p=0.09$ ).

Impact of duct at $24 \boldsymbol{h}$. At $24 \mathrm{~h}$ postnatal age, ductal diameter was inversely related to $\mathrm{SVC}$ flow volume $\left(\mathrm{R}^{2}=\right.$ $0.113, p=0.003)$ and positively related to $\operatorname{LVO}\left(\mathrm{R}^{2}=0.135\right.$, $p=0.008)$ on univariate analysis. Ductal diameter was not associated with volume of DAo flow or RVO. The inverse association between ductal diameter and SVC flow remained significant ( $p=0.001$ ) when correcting for birth weight, birth weight $\mathrm{z}$-score, and antenatal steroid use with multivariate analysis, but not when correcting for respiratory status $(p=$ 0.11). However, only 28 infants had $\mathrm{PCO}_{2}$ levels measured at the time of the echocardiogram.

Infants with ductal diameter greater than the median had lower SVC flow $(p=0.04)$ and lower DAo flow $(p=0.02)$ than infants with smaller ducts, despite higher LVO $(p=$ 0.01 ) (Table 2). There was no difference in RVO between the groups.

Of the 37 infants with duct diameter greater than the median at $24 \mathrm{~h}, 17(46 \%)$ had reversal of diastolic DAo flow. These 17 infants had increased LVO $(p=0.01)$ and decreased DAo flow volume ( $p=0.0001)$ when compared with infants with 
larger ducts but no reversal of diastolic DAo flow. However, there were no differences in SVC flow $(p=0.68)$ or RVO $(p=0.22)$ between the groups. Ratio of lower body to upper body perfusion was significantly lower in infants with DAo flow reversal ( 1.05 versus $2.00, p=0.01$ ).

Impact of duct at $48 \boldsymbol{h}$. At $48 \mathrm{~h}$ postnatal age, ductal diameter was inversely related to SVC flow volume $\left(\mathrm{R}^{2}=\right.$ $0.075, p=0.01)$ and DAo flow volume $\left(\mathrm{R}^{2}=0.079, p=\right.$ $0.01)$; and positively related to $\mathrm{LVO}\left(\mathrm{R}^{2}=0.354, p<0.0001\right)$ and $\mathrm{RVO}\left(\mathrm{R}^{2}=0.060, p=0.03\right)$ on univariate analysis. The inverse association between ductal diameter and SVC flow remained significant $(p=0.03)$ when correcting for birth weight, birth weight $\mathrm{z}$-score, and antenatal steroid use, but not when correcting for respiratory status $(p=0.17)$. However, only 28 infants had $\mathrm{PCO}_{2}$ levels measured at the time of the echocardiogram.

Infants with ductal diameter greater than the median had lower SVC flow $(p=0.004)$, higher LVO $(p<0.0001)$, and higher $\operatorname{RVO}(p=0.006)$ than infants with smaller ducts. There was no difference in DAo flow volume between the groups.

Of the 40 infants with duct diameter greater than the median of $1.4 \mathrm{~mm}$ at $48 \mathrm{~h}, 18(45 \%)$ had reversal of diastolic DAo flow. These 18 infants had increased LVO $(p=0.002)$ and decreased DAo flow volume $(p=0.002)$ when compared with infants with larger ducts but no reversal of diastolic DAo flow. However, there were no differences in SVC flow $(p=0.33)$ or
RVO ( $p=0.88$ ) between the groups. Ratio of lower body to upper body perfusion showed a trend to be lower in infants with DAo flow reversal (1.11 versus 1.87, $p=0.06$ ).

Summary of results. Associations of ductal size and DAo flow reversal with measurements of perfusion are shown in Table 3. The associations of diastolic DAo flow patterns with LVO, DAo flow, and SVC flow in infants with duct diameters greater than the median at 5, 12, 24, and $48 \mathrm{~h}$ are shown in Figure 1.

\section{DISCUSSION}

This study has shown that, while increased ductal size is associated with decreased volume of SVC flow at 12, 24, and $48 \mathrm{~h}$ postnatal age, this association does not persist when correcting for respiratory status on multivariate analysis. In addition, diastolic DAo flow reversal is not associated with decreased SVC flow volume at any time in the first $48 \mathrm{~h}$ of postnatal life in the preterm infants with large ducts in our cohort. Presence of diastolic DAo reversal is more strongly associated with increased LVO than ductal size in our cohort, and therefore seems to be a more accurate marker of volume of ductal shunt. It is quite possible then that the apparent relationship between ductal size and decreased SVC flow volume is spurious, with both low SVC flow and ductal size being related to respiratory status or immaturity. It seems that most infants with large ducts and high-volume ductal shunting

Table 2. LVO and RVO, and SVC and DAo flow volumes at 5, 12, 24, and 48 h postnatal age in 80 preterm infants

\begin{tabular}{|c|c|c|c|c|c|c|c|c|}
\hline \multirow[b]{3}{*}{ Time } & \multicolumn{4}{|c|}{ LVO } & \multicolumn{4}{|c|}{ RVO } \\
\hline & \multicolumn{2}{|c|}{ All infants } & \multicolumn{2}{|c|}{$\begin{array}{c}\text { Infants with } \\
\text { duct }>\text { median }\end{array}$} & \multicolumn{2}{|c|}{ All infants } & \multicolumn{2}{|c|}{$\begin{array}{c}\text { Infants with } \\
\text { duct }>\text { median }\end{array}$} \\
\hline & $<$ Median & $>$ Median & Reversal & $\begin{array}{c}\text { No } \\
\text { reversal }\end{array}$ & $<$ Median & $>$ Median & Reversal & $\begin{array}{c}\text { No } \\
\text { reversal }\end{array}$ \\
\hline \multirow[t]{2}{*}{$5 \mathrm{~h}$} & 310 & 326 & $351^{*}$ & $284 *$ & 340 & 309 & 304 & 330 \\
\hline & $159-493$ & $173-500$ & $209-500$ & $173-454$ & $100-584$ & $141-616$ & $184-451$ & $141-616$ \\
\hline \multirow[t]{2}{*}{$12 \mathrm{~h}$} & 282 & 295 & $346 \dagger$ & $268 \dagger$ & 374 & 337 & 356 & 313 \\
\hline & $159-440$ & $151-548$ & $237-548$ & $151-461$ & $160-542$ & $166-627$ & $204-473$ & $166-627$ \\
\hline \multirow[t]{2}{*}{$24 \mathrm{~h}$} & 288II & 348II & 398II & 312II & 413 & 428 & 435 & 410 \\
\hline & $177-483$ & $239-655$ & $259-655$ & $239-450$ & $242-758$ & $175-606$ & $175-606$ & $192-571$ \\
\hline \multirow[t]{4}{*}{$48 \mathrm{~h}$} & $262 \dagger$ & $386 \dagger$ & $450 \dagger$ & $349 \dagger$ & $389 \dagger$ & $448 \dagger$ & 447 & 447 \\
\hline & $155-437$ & $218-689$ & $305-689$ & $218-517$ & $200-594$ & $135-974$ & $135-974$ & $271-772$ \\
\hline & \multicolumn{4}{|c|}{ SVC flow } & \multicolumn{4}{|c|}{ DAo flow } \\
\hline & & & $\begin{array}{r}\text { Int } \\
\text { duct }\end{array}$ & $\begin{array}{l}\text { vith } \\
\text { edian }\end{array}$ & & & $\begin{array}{l}\text { In } \\
\text { duc }\end{array}$ & $\begin{array}{l}\text { vith } \\
\text { edian }\end{array}$ \\
\hline Time & $<$ Median & $>$ Median & Reversal & $\begin{array}{c}\text { No } \\
\text { reversal }\end{array}$ & $<$ Median & $>$ Median & Reversal & $\begin{array}{l}\text { No } \\
\text { reversal }\end{array}$ \\
\hline \multirow[t]{2}{*}{$5 \mathrm{~h}$} & 89 & 87 & 90 & 81 & 129 & 115 & 113 & 136 \\
\hline & $34-186$ & $19-225$ & $48-140$ & $19-225$ & $54-285$ & $59-335$ & $69-185$ & $59-335$ \\
\hline \multirow[t]{2}{*}{$12 \mathrm{~h}$} & $105^{*}$ & $83 *$ & 76 & 86 & 124 & 124 & 115 & 132 \\
\hline & 21-209 & $34-179$ & $34-179$ & $37-148$ & 55-202 & $46-266$ & $46-172$ & $53-266$ \\
\hline \multirow[t]{2}{*}{$24 \mathrm{~h}$} & $96 *$ & $84 *$ & 87 & 81 & $150^{*}$ & $135^{*}$ & $107 \dagger$ & $165 \dagger$ \\
\hline & $48-193$ & $35-163$ & $35-148$ & $51-163$ & $65-255$ & $29-249$ & $29-156$ & $98-248$ \\
\hline \multirow[t]{2}{*}{$48 \mathrm{~h}$} & $110 \dagger$ & $91 \dagger$ & 90 & 91 & 158 & 135 & $104 \dagger$ & $163 \dagger$ \\
\hline & $64-179$ & $29-176$ & $29-167$ & $30-176$ & $86-242$ & $43-261$ & 43-194 & $75-261$ \\
\hline
\end{tabular}

Results are shown for infants with duct diameter above and below the median at each time point, and in infants with duct diameter greater than the median in the presence and absence of diastolic DAo flow reversal. All values are in $\mathrm{mL} / \mathrm{kg} / \mathrm{min}$; median and range are shown.

$* p<0.05$, I $p<0.01, \dagger p<0.001$. 
Table 3. Associations of ductal size and DAo flow reversal at 5, 12, 24, and 48 h postnatal age in 80 preterm infants

\begin{tabular}{|c|c|c|c|c|}
\hline & $5 \mathrm{~h}$ & $12 \mathrm{~h}$ & $24 \mathrm{~h}$ & $48 \mathrm{~h}$ \\
\hline$\uparrow$ Duct size, univariate analysis & No association & $\downarrow$ SVC flowII & $\begin{array}{l}\downarrow \text { SVC flow } \\
\uparrow \text { LVOI }\end{array}$ & $\begin{array}{l}\downarrow \text { SVC flow } \mathbb{I} \\
\downarrow \text { DAo flow } \mathbb{I} \\
\uparrow \text { LVO } \dagger \\
\uparrow \text { RVO* }^{*}\end{array}$ \\
\hline Duct size $>$ median & No association & $\downarrow$ SVC flow* & $\begin{array}{l}\downarrow \text { SVC flow* } \\
\downarrow \text { DAo flow* } \\
\uparrow \text { LVOI }\end{array}$ & $\begin{array}{ll}\downarrow & \text { SVC flow } \mathbb{I} \\
\uparrow & \text { LVO } \dagger \\
\uparrow & \text { RVOI }\end{array}$ \\
\hline Of infants with duct $>$ median, presence of DAo reversal & $\uparrow \operatorname{LVO}(p=0.053)$ & $\uparrow \mathrm{LVO}^{\dagger}$ & $\begin{array}{l}\uparrow \text { LVOII } \\
\downarrow \text { DAo flow } \dagger\end{array}$ & $\begin{array}{l}\uparrow \text { LVOII } \\
\downarrow \text { DAo flow } \mathbb{}\end{array}$ \\
\hline
\end{tabular}

$* p<0.05, \mathbb{I} p<0.01, \dagger p<0.001$.
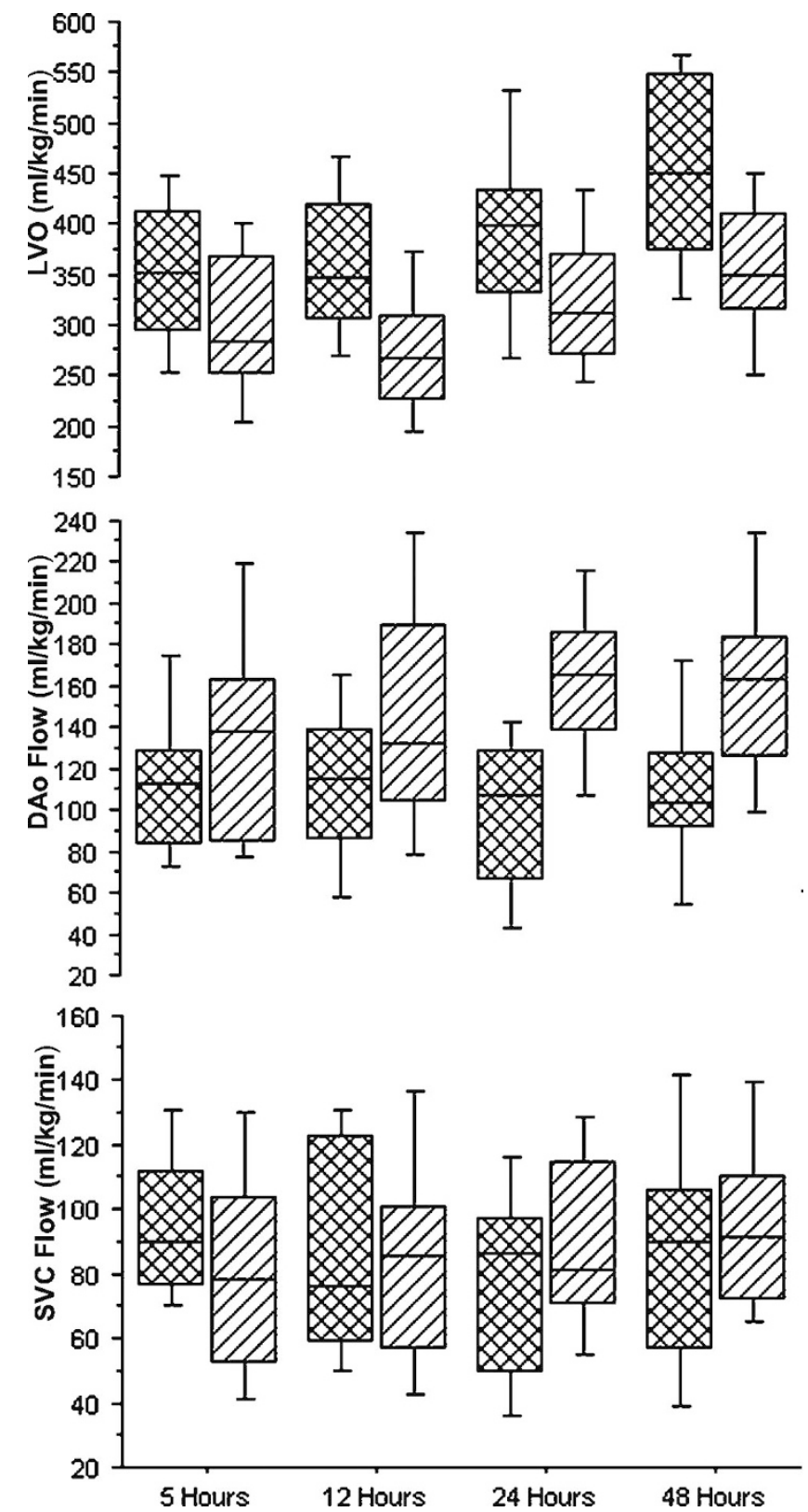

Figure 1. LVO and DAo and SVC flow volumes in infants with ductal diameter greater than the median value at $5,12,24$, and $48 \mathrm{~h}$. Values are compared at each age between infants with (hatched) and without (lined) retrograde diastolic flow in the descending aorta. have increased LVO and preserved SVC (upper body) flow in the first $48 \mathrm{~h}$. After $12 \mathrm{~h}$ of age, diastolic DAo reversal in infants with large ducts is increasingly associated with decreased DAo flow volume. Lower body flow may therefore not be preserved in the presence of high-volume ductal shunt after $12 \mathrm{~h}$ of age.

The volume of ductal shunt depends both on the diameter of the duct and the pressure gradient across it. Healthy preterm infants can achieve ductal constriction in a similar timeframe as term infants (25), while sick preterm infants show more variable constriction (8). Postnatal fall in pulmonary pressure has previously been shown to occur slowly in some preterm infants such that systemic and pulmonary pressures remain balanced and ductal shunting is bidirectional (26). In our cohort, the vast majority of ductal shunting was purely systemic-to-pulmonary by $12 \mathrm{~h}$ postnatal age. Antenatal corticosteroid use and the administration of surfactant have been associated with a more rapid decrease in pulmonary pressure (13), and it is possible that these factors influenced the direction of shunting in our cohort.

Reversal of diastolic DAo flow (as blood in the descending aorta is 'stolen' backwards and through the duct) is considered a reliable marker of high volume ductal shunt (24). In our cohort of infants, diastolic DAo reversal occurred as early as $4 \mathrm{~h}$ after birth, and was seen in $34 \%$ and $46 \%$ of infants with large ducts at 12 and $24 \mathrm{~h}$, respectively. Our data show that ductal shunting in the first $48 \mathrm{~h}$ of postnatal life in preterm infants is predominantly systemic-to-pulmonary, and that significant volumes of blood may be shunted at this time.

Preservation of systemic perfusion in the presence of ductal shunting depends on LVO increasing by an equivalent volume to that being shunted through the ductus. That myocardial contractility may be impaired in preterm infants $(15,27)$ raises the possibility that ductal steal in the first postnatal day may lead to decreased systemic perfusion. However, high-volume ductal shunting occurs into a pulmonary circulation of low resistance, and there is some suggestion from animal studies that even the immature myocardium is able to significantly increase LVO when afterload is low (28). In addition, ductal shunting leads to increased venous return to the left atrium, increasing preload to the left ventricle. This allows increased left ventricular stroke volume through the Frank-Starling mechanism, which does not require an increase in inherent contractility (29). 
In our cohort of infants, increased ductal diameter was associated with increased LVO at 24 and $48 \mathrm{~h}$, and diastolic DAo reversal in infants with large ducts was associated with increased LVO at 5, 12, 24, and $48 \mathrm{~h}$.

Increased ductal diameter at 12,24 , and $48 \mathrm{~h}$ postnatal age was associated with decreased SVC flow volume on univariate analysis. However, this association did not persist when correcting for respiratory status. While this may be due to the limited numbers of infants in whom $\mathrm{PCO}_{2}$ measurements were available, it may also be because the association between ductal size and SVC flow volume was due to the confounding variable of respiratory disease, immaturity, or other unidentified confounding factors.

To clarify this issue, we used the presence or absence of diastolic DAo flow reversal (as a marker of volume of ductal shunt) to identify those infants with high- or low-volume ductal shunt, only within a subgroup of infants who had ductal diameters above the median at each time point. Diastolic DAo flow reversal in infants with large ducts was not associated with decreased volume of SVC flow at any time.

Despite the observed increases in LVO, infants with large ducts and diastolic DAo flow reversal appeared to have decreased volume of descending aortic blood flow at 12, 24, and $48 \mathrm{~h}$. These infants also tended to have decreased ratios of lower body to upper body perfusion. Thus, ductal steal may be occurring preferentially from the lower body (21) (just as pulmonary-to-systemic shunting occurs preferentially into the lower body, causing a discrepancy between pre- and postductal saturations in infants with persistent fetal circulation). Systemic-to-pulmonary ductal shunt could occur preferentially from the descending portion of the aorta because of the duct's orientation toward the distal aorta $(30,31)$, and the existence of preferential shunting is supported by the observation that, in the presence of ductal shunt, diastolic flow reversal is more common in the renal than the cerebral vasculature, despite the vascular beds having similar flow patterns when the duct is closed $(21,32)$.

This study has a number of limitations. Blood gas results are not available on all study infants, which prevents any firm conclusions being drawn on the role of respiratory disease acting as a confounder on the association between ductal size and low SVC flow. However, as the study did not set out to address this specific issue, blood gases were taken according to clinical indications and consent was not obtained for additional blood gas testing. While repeatability of measures of ductal diameter taken from a single video recording has been shown to be reasonable (coefficient of variation 12\%) (8), the true repeatability of assessment of this dynamic vessel is not known. Variability in assessment of ductal diameter could both produce erroneous associations and mask other true associations. Assessments of volume of DAo flow were made based on average DAo diameter throughout the cardiac cycle (22), which will slightly overestimate the volume of retrograde flow that occurs in diastole when the vessel diameter is less, and therefore tend to underestimate total DAo flow volume in these infants. However, it is unlikely that these inaccuracies would be sufficiently large to produce the $35 \%$ decrease seen when comparing DAo flow volume in infants with and without diastolic DAo reversal.

Findings from this study of flow in the first $48 \mathrm{~h}$ cannot be extrapolated to later in the postnatal period. After this time, pulmonary pressure continues to fall and ductal shunting has increased impact on blood pressure $(4,33)$ and patterns of cerebral perfusion $(34,35)$. In addition, it should be noted that the finding that upper body perfusion is maintained in the presence of ductal shunt is drawn from mean values seen across a large cohort of preterm infants, and it is clear that the transitional circulation varies greatly between individuals $(17,36)$. Given that these infants need to increase LVO; decreased myocardial contractility, hypovolemia, or sepsis may still result in impaired upper body perfusion in some individuals some of the time. Nevertheless, it would seem likely that such stressors would have a greater effect on the lower body, and particularly the gut, potentially leading to impaired digestion, impaired gastric motility, and even necrotizing enterocolitis. It may be that a subgroup of these infants would benefit from ductal closure in the first postnatal days.

Even in early postnatal life, ductal shunting is predominantly systemic-to-pulmonary, and significant volumes of shunt may occur. In most infants, LVO increases in the presence of ductal shunt, even in early postnatal life. In infants with large ducts, diastolic DAo flow reversal indicates an increased volume of ductal shunt, but this is not associated with decreased upper body perfusion in the first $48 \mathrm{~h}$ of postnatal life. However, lower body perfusion may be impaired, particularly into the second day.

Acknowledgments. The authors thank the nursing staff at the Neonatal Intensive Care Unit, Auckland City Hospital, for their cooperation and support during the study.

\section{REFERENCES}

1. Laughon MM, Simmons MA, Bose CL 2004 Patency of the ductus arteriosus in the premature infant: is it pathologic? Should it be treated? Curr Opin Pediatr 16:146151

2. Raval MV, Laughon MM, Bose CL, Phillips JD 2007 Patent ductus arteriosus ligation in premature infants: who really benefits, and at what cost? J Pediatr Surg 42:69-75

3. Evans N 2003 Current controversies in the diagnosis and treatment of patent ductus arteriosus in preterm infants. Adv Neonatal Care 3:168-177

4. Knight DB 1992 Patent ductus arteriosus: how important to which babies? Early Hum Dev 29:287-292

5. Skinner J 2001 Diagnosis of patent ductus arteriosus. Semin Neonatol 6:49-61

6. Kluckow M, Evans N 2000 Ductal shunting, high pulmonary blood flow, and pulmonary hemorrhage. J Pediatr 137:68-72

7. Chorne N, Leonard C, Piecuch R, Clyman RI 2007 Patent ductus arteriosus and its treatment as risk factors for neonatal and neurodevelopmental morbidity. Pediatrics 119:1165-1174

8. Evans N, Iyer P 1995 Longitudinal changes in the diameter of the ductus arteriosus in ventilated preterm infants: correlation with respiratory outcomes. Arch Dis Child Fetal Neonatal Ed 72:F156-F161

9. Cooke RW 2005 Perinatal and postnatal factors in very preterm infants and subsequent cognitive and motor abilities. Arch Dis Child Fetal Neonatal Ed 90:F60 F63

10. Van Overmeire B 2007 Patent ductus arteriosus: how aggressive should we be? Neonatology 91:318

11. Seppanen MP, Kaapa PO, Kero PO 1995 Hemodynamic prediction of complications in neonatal respiratory distress syndrome. J Pediatr 127:780-785

12. Skinner J 1997 The effects of surfactant on haemodynamics in hyaline membrane disease. Arch Dis Child Fetal Neonatal Ed 76:F67-F69

13. Hamdan AH, Shaw NJ 1998 Changes in pulmonary artery pressure during the acute phase of respiratory distress syndrome treated with three different types of surfactant. Pediatr Pulmonol 25:191-195

14. Evans N, Kluckow M 1996 Early determinants of right and left ventricular output in ventilated preterm infants. Arch Dis Child Fetal Neonatal Ed 74:F88-F94 
15. Takahashi Y, Harada K, Kishkurno S, Arai H, Ishida A, Takada G 1997 Postnatal left ventricular contractility in very low birth weight infants. Pediatr Cardiol 18:112-117

16. Kluckow M, Evans N 2000 Superior vena cava flow in newborn infants: a novel marker of systemic blood flow. Arch Dis Child Fetal Neonatal Ed 82:F182-F187

17. Kluckow M, Evans N 2000 Low superior vena cava flow and intraventricular haemorrhage in preterm infants. Arch Dis Child Fetal Neonatal Ed 82:F188-F194

18. West CR, Groves AM, Williams CE, Harding JE, Skinner JR, Kuschel CA, Battin MR 2006 Early low cardiac output is associated with compromised electroencephalographic activity in very preterm infants. Pediatr Res 59:610-615

19. Hunt RW, Evans N, Rieger I, Kluckow M 2004 Low superior vena cava flow and neurodevelopment at 3 years in very preterm infants. J Pediatr 145:588-592

20. Walther FJ, Siassi B, King J, Wu PY 1986 Blood flow in the ascending and descending aorta in term newborn infants. Early Hum Dev 13:21-25

21. Shimada S, Kasai T, Hoshi A, Murata A, Chida S 2003 Cardiocirculatory effects of patent ductus arteriosus in extremely low-birth-weight infants with respiratory distress syndrome. Pediatr Int 45:255-262

22. Groves AM, Kuschel CA, Knight DB, Skinner J 2007 Echocardiographic assessment of blood flow volume in the SVC and descending aorta in the newborn infant. Arch Dis Child Fetal Neonatal Ed [Epub ahead of print]

23. Tsai-Goodman B, Martin RP, Marlow N, Skinner JR 2001 The repeatability of echocardiographic determination of right ventricular output in the newborn. Cardiol Young 11:188-194

24. Evans N, Iyer P 1994 Assessment of ductus arteriosus shunt in preterm infants supported by mechanical ventilation: effect of interatrial shunting. J Pediatr 125:778-785

25. Evans NJ, Archer LN 1990 Postnatal circulatory adaptation in healthy term and preterm neonates. Arch Dis Child 65:24-26
26. Skinner JR, Boys RJ, Hunter S, Hey EN 1992 Pulmonary and systemic arterial pressure in hyaline membrane disease. Arch Dis Child 67:366-373

27. Toyono M, Harada K, Takahashi Y, Takada G 1998 Maturational changes in left ventricular contractile state. Int J Cardiol 64:247-252

28. Clyman RI, Roman C, Heymann MA, Mauray F 1987 How a patent ductus arteriosus effects the premature lamb's ability to handle additional volume loads. Pediatr Res 22:531-535

29. Berne RM, Levy MN 1993 Physiology CV Mosby, St Louis, MO

30. Abrams SE, Walsh KP 1993 Arterial duct morphology with reference to angioplasty and stenting. Int J Cardiol 40:27-33

31. Brezinka C, DeRuiter M, Slomp J, den Hollander N, Wladimiroff JW, Gittenberger-de Groot AC 1994 Anatomical and sonographic correlation of the fetal ductus arteriosus in first and second trimester pregnancy. Ultrasound Med Biol 20:219-224

32. Shimada S, Kasai T, Konishi M, Fujiwara T 1994 Effects of patent ductus arteriosus on left ventricular output and organ blood flows in preterm infants with respiratory distress syndrome treated with surfactant. J Pediatr 125:270-277

33. Evans N, Moorcraft J 1992 Effect of patency of the ductus arteriosus on blood pressure in very preterm infants. Arch Dis Child 67:1169-1173

34. Perlman JM, Hill A, Volpe JJ 1981 The effect of patent ductus arteriosus on flow velocity in the anterior cerebral arteries: ductal steal in the premature newborn infant. J Pediatr 99:767-771

35. Martin CG, Snider AR, Katz SM, Peabody JL, Brady JP 1982 Abnormal cerebral blood flow patterns in preterm infants with a large patent ductus arteriosus. J Pediatr 101:587-593

36. Drayton MR, Skidmore R 1987 Ductus arteriosus blood flow during first 48 hours of life. Arch Dis Child 62:1030-1034 